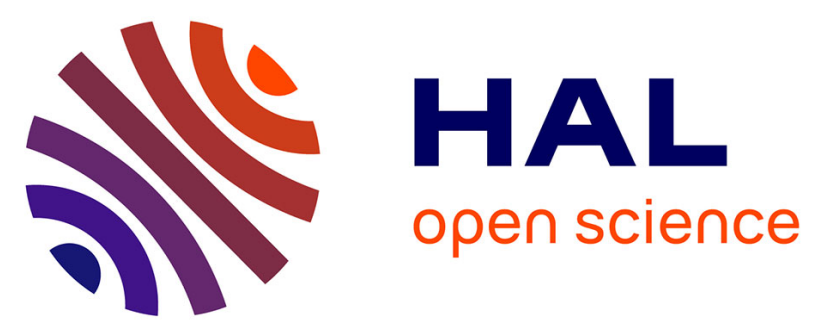

\title{
Toxicity, transfer and depuration of anatoxin-a (cyanobacterial neurotoxin) in medaka fish exposed by single-dose gavage
}

\author{
Simon Colas, Charlotte Duval, Benjamin Marie
}

\section{- To cite this version:}

Simon Colas, Charlotte Duval, Benjamin Marie. Toxicity, transfer and depuration of anatoxin-a (cyanobacterial neurotoxin) in medaka fish exposed by single-dose gavage. Aquatic Toxicology, In press, 10.1016/j.aquatox.2020.105422 . mnhn-02465304

\section{HAL Id: mnhn-02465304}

\section{https://hal-mnhn.archives-ouvertes.fr/mnhn-02465304}

Submitted on 3 Feb 2020

HAL is a multi-disciplinary open access archive for the deposit and dissemination of scientific research documents, whether they are published or not. The documents may come from teaching and research institutions in France or abroad, or from public or private research centers.
L'archive ouverte pluridisciplinaire HAL, est destinée au dépôt et à la diffusion de documents scientifiques de niveau recherche, publiés ou non, émanant des établissements d'enseignement et de recherche français ou étrangers, des laboratoires publics ou privés. 


\section{Journal Pre-proof}

Toxicity, transfer and depuration of anatoxin-a (cyanobacterial neurotoxin) in medaka fish exposed by single-dose gavage

Simon Colas (Investigation) (Formal analysis)<ce:contributorrole $>$ Visualisation)<ce:contributor-role $>$ Writing - originnal draft),

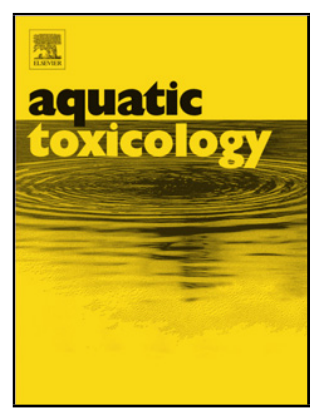
Charlotte Duval (Resources), Benjamin Marie (Conceptualization) (Methodology) (Supervision) (Writing - review and editing) (Funding acquisition)

PII:

S0166-445X(19)31051-3

DOI: https://doi.org/10.1016/j.aquatox.2020.105422

Reference:

AQTOX 105422

To appear in:

Aquatic Toxicology

Received Date:

12 December 2019

Revised Date:

15 January 2020

Accepted Date:

21 January 2020

Please cite this article as: Colas S, Duval C, Marie B, Toxicity, transfer and depuration of anatoxin-a (cyanobacterial neurotoxin) in medaka fish exposed by single-dose gavage, Aquatic Toxicology (2020), doi: https://doi.org/10.1016/j.aquatox.2020.105422

This is a PDF file of an article that has undergone enhancements after acceptance, such as the addition of a cover page and metadata, and formatting for readability, but it is not yet the definitive version of record. This version will undergo additional copyediting, typesetting and review before it is published in its final form, but we are providing this version to give early visibility of the article. Please note that, during the production process, errors may be discovered which could affect the content, and all legal disclaimers that apply to the journal pertain.

(C) 2020 Published by Elsevier. 


\title{
Toxicity, transfer and depuration of anatoxin-a (cyanobacterial neurotoxin) in medaka fish exposed by single-dose gavage
}

\author{
Simon COLAS ${ }^{1}$, Charlotte DUVAL ${ }^{1}$ and Benjamin MARIE ${ }^{1 *}$ \\ ${ }^{1}$ UMR 7245 CNRS/MNHN "Molécules de Communications et Adaptations des Micro-organismes", Muséum \\ National d'Histoire Naturelle, Paris - France \\ * Correspondence should be addressed to B.M. (bmarie@mnhn.fr)
}

\begin{abstract}
The proliferations of cyanobacteria are increasingly prevalent in many rivers and water bodies due especially to eutrophication. This work aims to study in female medaka fish the toxicity, the transfer and the depuration of the anatoxin-a, a neurotoxin produced by benthic cyanobacterial biofilms. This work will provide answers regarding acute toxicity induced by single gavage by anatoxin-a and to the risks of exposure by ingestion of contaminated fish flesh, considering that data on these aspects remain particularly limited.

The oral LD50 and NOAEL of a single dose of $( \pm)$-anatoxin-a were determined at 11.50 and $6.67 \mu \mathrm{g} . \mathrm{g}^{-1}$, respectively. Subsequently, the toxico-kinetics of the $( \pm)$-anatoxin-a was observed in the guts, the livers and the muscles of female medaka fish for 10 days. Anatoxin-a was quantified by high-resolution qTOF mass spectrometry coupled upstream to a UHPLC chromatographic chain. The toxin could not be detected in the liver after $12 \mathrm{~h}$, and in the gut and muscle after 3 days. Overall, the medaka fish do not appear to accumulate ( \pm )-anatoxin-a and to largely recover after $24 \mathrm{~h}$ following a single sub-acute oral liquid exposure at the NOAEL.
\end{abstract}

Keywords: cyanobacteria; neurotoxin; fish; toxicology; gavage; toxico-kinetics. 


\section{Introduction}

The worldwide proliferation of cyanobacterial blooms constitutes a serious environmental and economic problem that menaces wildlife and human health. Moreover, many cyanobacteria can produce potent hepatotoxins such as microcystin, cylindrospermopsin and nodularin, and/or neurotoxins such as anatoxin-a, homo-anatoxin-a, anatoxin-a(s) and saxitoxin (Sivonen \& Jones, 1999). Harmful cyanobacterial blooms in lakes have been described for decades; in rivers, however, first reports of animal deaths from toxic benthic cyanobacteria in many regions occurred only in the last 20 years (Wood et al., 2007). Since toxic benthic cyanobacteria in rivers have been documented in many countries and benthic taxa have been found to produce a large spectrum of those cyanotoxins, though most animal fatalities reported concerning benthic cyanobacteria were associated with the presence of anatoxin-a and/or homoanatoxin-a (for review Quiblier et al., 2013).

Anatoxin-a and homoanatoxin-a are potent neurotoxins produced by some planktonic and benthic strains of the genera Phormidium (syn. Kamptonema), Anabaena, Oscillatoria, Aphanizomenon, Cylindrospermum (Bouma-Gerson et al., 2018). Indeed, numerous fatal intoxications of animals, by anatoxin-a and homoanatoxin-a, have been reported all over the world (Gugger et al., 2005; Puschner et al., 2010; Wood et al., 2007). These alkaloids bind tightly to the nicotinic acetylcholine receptor, in the sub-nanomolar range, and thus provoke the death of animals almost immediately after ingestion (Wonnacott and Gallagher, 2006). Anatoxin-a, as a competitive agonist of acetylcholine, can bind its specific membrane receptors (mAChR), leading to a blockage of the neuromuscular signal transmission, causing muscle cell overstimulation (Carmichael, 1994; Aráoz et al. 2010). Acute effects in vertebrates include a rapid loss of coordination, a decreased of locomotor activity, a paralysis of the peripheral skeletal and respiratory muscles, causing symptoms such as loss of coordination, twitching, irregular breathing, tremors, altered gait and convulsions before death by acute asphyxia induced by respiratory arrest (Dittmann and Wiegand, 2006).

It is maybe because anatoxin-a is very unstable and labile in the water (Stevens and Krieger, 1991) and because no chronic effects have been described in mammals so far (Fawell et al., 1999), that this toxin has been considered of less environmental concern comparing to other cyanotoxins. Despite the acute neurotoxic effects of anatoxin-a, the consequence of the proliferation of anatoxins-a producing cyanobacterial biofilms on ecosystem health and aquatic organisms remains largely unknown. Despite, toxic benthic cyanobacterial mats have been associated with decreased macro-invertebrate diversity (Aboal et al., 2002), few studies have investigated the genuine toxicological effects of these compounds on aquatic organisms (Carneiro et al., 2015; Osswald et al., 2007b; Anderson et al., 2018). In some experiments performed on fishes, such as carps and goldfish, behavioural defects such as rapid opercular movement, abnormal swimming (Osswald et al., 2007a) and muscle rigidity (Carmichael et al., 1975) were observed. Oberemm et al. (1999) described also the alterations in heart rates in zebrafish embryos after exposure to anatoxin-a. Thus a scarcity of information regarding its capability of aquatic species to bio-concentrate and bioaccumulation anatoxin-a when administered by natural oral pathways, and its subsequent potential toxicological impacts on organisms still exist. In a previous study, Osswald and co-workers (2007b) found that anatoxin- 
a may be bioaccumulated by carps in significant levels $\left(0.768 \mu \mathrm{g} \cdot \mathrm{g}^{-1}\right.$ of carp weight). Whether this may have an impact on aquatic food webs is not yet known.

In this study, we wanted to study the toxico-kinetics of the anatoxin-a and its consecutive possibility of accumulation of in fish tissues. We use medaka model fish to be able to administrate, under controlled conditions by a single gavage, a predetermined dose of anatoxina in order to determine the dose-response toxicity parameters. In parallel, we follow the assimilation/depuration processes of fish gavaged with a no observable adverse effect level (NOAEL) dose during the 10 following days. As there is still a lack of reference and standardized protocol for anatoxins-a extraction from biological matrices, such as fish tissues, and for quantification analysis, we have also tested three different extraction procedures inspired by previously published works (Triantis et al., 2016) and describe a high accuracy detection method developed on UHPLC coupled HR-qTOF mass spectrometer using TASQ software. This present work provides significant outcomes for the investigation of fish contamination by anatoxin-a and the subsequent consequences on risk evaluation through human consumption.

\section{Material and methods}

\section{Chemicals}

In solution certified (+)-Anatoxin-a and dry ( \pm )-Anatoxin-a were purchased from CRMNRC (Canada) and Abcam (UK), respectively. The purity and the concentration of the daily reconstituted $( \pm)$-Anatoxin-a in ultra-pure water were initially checked by LC-MS/MS as described in the following protocol. UHPLC-MS grade methanol and acetonitrile were purchased from Bio TechnoFix (France). Proteomics grade formic acid was purchased from Sigma-Aldrich (Germany).

\section{Cyanobacteria cultures and Anatoxin-a extraction procedure test}

Three monoclonal non-axenic cultures of Phomidium (syn. Kamptonema) sp. (PMC 1001.17, 1007.17 and 1008.17) maintained at $25{ }^{\circ} \mathrm{C}$ in $15 \mathrm{~mL}$ vessels with $\mathrm{Z8}$ media in the PMC (Paris Museum Collection) of living cyanobacteria. A larger volume of all strains was simultaneously cultivated during one month in triplicates in $250 \mathrm{~mL}$ Erlenmeyer vessels at 25 ${ }^{\circ} \mathrm{C}$ using a Z8 medium with a $16 \mathrm{~h}: 8 \mathrm{~h}$ light/dark cycle $\left(60 \mu \mathrm{mol} \cdot \mathrm{m}^{-2} \cdot \mathrm{s}^{-1}\right)$. Cyanobacterial cells were centrifuged (at $4,000 \mathrm{~g}$ for $10 \mathrm{~min}$ ), then freeze-dried and stored at $-80{ }^{\circ} \mathrm{C}$ before anatoxina extraction. The lyophilized cells were weighted, sonicated $2 \mathrm{~min}$ in a constant ratio of $100 \mu \mathrm{L}$ of solvent for $1 \mathrm{mg}$ of dried biomass, centrifuged at $4{ }^{\circ} \mathrm{C}(12,000 \mathrm{~g} ; 10 \mathrm{~min})$, then the supernatant was collected and directly analysed by mass spectrometry. We have presently tested in triplicates the extraction efficiency of three different solvent mixtures already propositioned for anatoxin-a extraction (Bogialli et al., 2006; Rellan et al., 2007; Triantis et al., 2016; Haddad et al., 2019), comprising: a pure water solution acidified with $0.1 \%$ formic acid ("Water" extraction), a $25 \%$ acetonitrile solution acidified with $0.1 \%$ formic acid ("Acetonitrile" extraction), and a $75 \%$ methanol solution acidified with $0.1 \%$ formic acid ("Methanol" extraction). The efficiency of the extraction procedure was significantly determined according to Dunn's post-hoc test performed after Krustal-Wallis non-parametric tests process on $\mathrm{R}$ software. 


\section{Fish experimentation}

Experiments on medaka fish were conducted according to European community good practices, validated by the ethical "comité Cuvier" (Author. APAFiS\#19417$2019022711043436 \mathrm{v} 4$ ) and under the supervision of accredited personnel (B.M.). Adult female medaka fishes (Oryzias latipes) of the inbred cab strain, above 6-month old and $1 \pm 0.1 \mathrm{~g}$ of wet weight were used in all experiments. They were raised in $20 \mathrm{~L}$ glass aquaria filled with a continuously aerated mixture of tap water and reverse osmosis filtered water $(1 / 3-2 / 3$, respectively), which was changed once a week. Fish were maintained at $25 \pm 1{ }^{\circ} \mathrm{C}$, with a 12 h:12 h light:dark standard cycle.

Fish were individually anaesthetized in $0.1 \%$ tricaine methanesulfonate (MS-222; Sigma, St. Louis, MO), and then, briefly, $2 \mu \mathrm{L}$ of a ( \pm )-anatoxin-a mixture containing from 0.2 to 20 $\mu \mathrm{g}$ of $( \pm$ )-anatoxin-a ( $\mathrm{n}=3-6$, the number being adapted in order to confirm the observed adverse effects) in water saturated with phenol red dyes was administered by gavage performed with a smooth plastic needle. Control fishes were gavaged with $2 \mu \mathrm{L}$ of water saturated with phenol red dyes. For all individual, the efficiency of the gavage uptakes was carefully checked according to the total lack of phenol red release from the mouth or the gill opercula of the fish, otherwise, the individual was immediately sacrificed. The fish was then instantaneously placed in fresh water tanks and individually observed during $30 \mathrm{~min}$ to detect any behavioural sign of anatoxin-a neurotoxicity, that comprises: paralysis, decrease of breathing activity through opercular movements, locomotors activity or buoyancy default. Indeed, when gavaged with none toxic dose or control mixture, fish promptly recovers from anaesthesia within a minute and rapidly normal swimming activity (in less than 3-5 minutes). But, alternatively, the toxicological effects of toxic doses of $( \pm)$-anatoxin-a induce immediate neuro-muscular pathology and provoke a full breathing stop. After 30 min of observation, the individual was declared as "dead" as no recover was observed and the experiment was then concluded, then all fishes were anaesthetized in $0.1 \%$ tricaine methanesulfonate (MS-222) and euthanized. The medium lethal dose (LD50) and the no observable adverse effect limit (NOAEL) were calculated from toxicological results by logistic regression after log transformation of the concentration values using $\mathrm{R}$ software.

For toxico-kinetics investigations, adult female medaka fish were similarly gavaged individually by a single NOAEL dose, then placed in fresh water and collected after $1 \mathrm{~h}, 3 \mathrm{~h}, 6$ h, 12 h, 24 h, $3 \mathrm{~d}, 6 \mathrm{~d}$ or $10 \mathrm{~d}$ of maintaining under classical conditions ( $\mathrm{n}=5$ individuals for each interval). Accordingly, all fishes were anaesthetized in $0.1 \%$ tricaine methanesulfonate, sacrificed, dissected, and the whole gut, the liver and the muscles were sampled and flash-frozen in liquid nitrogen, and kept frozen at $-80^{\circ} \mathrm{C}$ prior to analysis.

\section{Anatoxin- $a$ and metabolite extraction from fish tissues}

The fish tissues were weighted then sonicated $2 \mathrm{~min}$ in a constant ratio of $10 \mu \mathrm{L}$ of $75 \%$ methanol solution acidified with $0.1 \%$ formic acid (this extraction procedure showing the best efficiency) for $1 \mathrm{mg}$ of wet biomass for guts and livers, and lyophilised biomass for muscles, ground into a fine powder on Tissue-lyser (with $5 \mathrm{~mm}$ steel beads, Qiagen), centrifuged at $4{ }^{\circ} \mathrm{C}$ $(12,000 \mathrm{~g} ; 10 \mathrm{~min})$; then the supernatant was collected and directly analysed by mass spectrometry. The efficiency of the extraction was estimated according to the recovery rate 
determined in triplicates by injecting a known amount of ( \pm )-anatoxin-a to negative samples before extraction (method A) or just before the mass spectrometry analysis (method B).

\section{Anatoxin-a detection and quantification}

Ultra high-performance liquid chromatography (UHPLC) was performed on $2 \mu \mathrm{L}$ of each of the metabolite extracts using a Polar Advances II 2.5 pore $\mathrm{C}_{18}$ column (Thermo) at a 300 $\mu \mathrm{L} . \mathrm{min}^{-1}$ flow rate with a linear gradient of acetonitrile in $0.1 \%$ formic acid (5 to $90 \%$ in 21 min). The metabolite contents were analyzed in triplicate for each strain using an electrospray ionization hybrid quadrupole time-of-flight (ESI-QqTOF) high-resolution mass spectrometer (Maxis II ETD, Bruker) at $2 \mathrm{~Hz}$ speed on simple MS mode and subsequently on broad-band Collision Ion Dissociation (bbCID) MS/MS mode on the $50-1500 \mathrm{~m} / \mathrm{z}$ range. Calibrants, composed by serial dilutions of (+)-anatoxin-a, and negative control (phenylalanine) were analysed similarly. The raw data were automatically processed with the TASQ 1.4 software for internal recalibration $(<0.5 \mathrm{ppm}$ for each sample, as an internal calibrant of Na formate was injected at the beginning of each analysis) for global screening and quantification, and molecular featuring, respectively. Then, the automatic screening and quantification of anatoxina were performed with threshold parameters set to the recommended default value for the Maxis II mass spectrometer $(\Delta \mathrm{RT}<0.4 \mathrm{~s}, \Delta \mathrm{m} / z<3 \mathrm{ppm}$, mSigma $<50$ and $\mathrm{S} / \mathrm{N}<5)$. Quantification was performed according to the integration of the area under the peaks and calibration curve was performed with certified standards.

\section{Analysis of liver metabolomes}

Metabolites composition of the fish livers were analysed by injection of $2 \mu \mathrm{L}$ of the $75 \%$ methanol extracts on an UHPLC (ELUTE, Bruker) coupled with a high-resolution mass spectrometer (ESI-Qq-TOF Compact, Bruker) at $2 \mathrm{~Hz}$ speed on simple MS mode and subsequently on broad-band Collision Ion Dissociation (bbCID) or autoMS/MS mode on the $50-1500 \mathrm{~m} / \mathrm{z}$ range. The analyte annotations were performed according to precise mass and isotopic and fragmentation MS/MS patterns, as previously described (Kim Tiam et al., 2019). The feature peak list was generated from recalibrated MS spectra $(<0.5 \mathrm{ppm}$ for each sample, as an internal calibrant of $\mathrm{Na}$ formate was injected at the beginning of each analysis) within a 1-15 min window of the LC gradient, with a filtering of 5,000 count of minimal intensity, a minimal occurrence in at least $50 \%$ of all samples, and combining all charge states and related isotopic forms using MetaboScape 4.0 software (Bruker). The intensity data table of the 591 extracted analytes was further treated using MetaboAnalyst 4 tool (Chong et al., 2019) for Pareto's normalization, ANOVA, PCA and PLS-DA, and data representation by heatmap with hierarchical clustering, loading plots and box plots.

Unsupervised PCA models were first used to evaluate the divide between experimental groups, while supervised PLS-DA models allowed us to increase the separation between sample classes and to extract information on discriminating metabolites. The PLS-DA allowed the determination of discriminating metabolites using the analytes score values of the variable importance on projection (VIP) indicating the respective contribution of a variable to the discrimination between all of the experimental classes of samples. The higher score being in agreement with a strongest discriminatory ability and thus constitutes a criterion for the selection of the analytes as discriminative components. The PLS models were tested for over 
fitting with methods of permutation tests. The descriptive, predictive and consistency performance of the models was determined by $R^{2}, Q^{2}$ values and permutation test results $(n=$ $100)$, respectively.

\section{Results}

Anatoxin-a extraction and analysis

Anatoxin-a specific mass spectrometry detection and quantification were automatically determined with high accuracy using TASQ (Bruker, Germany) from raw data generated by LC-MS/MS system according to the observation of analytes signal exhibiting targeted precise molecular mass, retention time, isotopic pattern and fragmentation ions (Fig. 1A-B). This approach allows to discriminate both (+)-anatoxin-a and (-)-anatoxin-a isomers according to their respective retention times (Fig. 1C), as well as phenylalanine (Fig. 1D) used as a negative control, that does not exhibit any signal interaction with the anatoxin-a quantification. Standard solutions containing a certified quantity of (+)-anatoxin-a was diluted in ultra-pure water in the range of $5 \mu \mathrm{g} \cdot \mathrm{mL}^{-1}-2 \mathrm{ng} \cdot \mathrm{mL}^{-1}$ and used for calibration with good linearity of the calibration curve exhibiting a correlation coefficient with $\mathrm{R}^{2}=0.99326$ (Fig. 1E). Quantification of the (+)-anatoxin-a was performed according to the area-under-the-curve signal that was automatically integrated and processed by the software that provides calculation details comprising all diagnostic elements in the report table generate for each analysis (Fig 1F).

Anatoxin-a extraction efficiency was assayed in triplicates with 3 different Phormidium (syn. Kamptonema) strains using rather an acetonitrile, methanol or water solvent solutions. In our hands, the $75 \%$ methanol acidified with $0.1 \%$ formic acid present significantly higher efficiency for anatoxin-a extraction (Table 1) and was further performed for the fish tissue extraction. The detection and quantitation limits (LOD and LOQ) and recovery rate were determined for the instrument measurement and the global quantification method by triplicate injections of the different fish tissues spiked with of determined doses of (+)-anatoxin-a. This (+)anatoxin-a that were administrated either before the extraction (method A) or just before the sample analysis by mass spectrometry (method B) (table 2). The LOD and LOQ of the technics were estimated to be in the same range as those previously described (Triantis et al., 2016). These investigations also show that anatoxin-a extraction and detection recovery rate vary from 25 to $78 \%$ and from 51 to $126 \%$, respectively, according to the tissue analysis with the guts and the muscles presenting the best and the worth recovery scores, respectively.

\section{Anatoxin-a toxicology}

Fish were exposed to anatoxin-a though the oral pathway (rather than by balneation of injection) in order to be representative to natural exposure route through the toxinogeneous biofilm consumption (being the main natural contamination source), and, overall, to be able to precisely control the administered doses, as precisely required for the reproducible determination of toxicological and assimilation/depuration parameters. All individuals, including negative controls, gavaged with $\left( \pm\right.$ )-anatoxin-a doses up to $6.67 \mu \mathrm{g}^{-\mathrm{g}^{-1}}$ survive without presenting any apparent symptoms of toxicosis and were able to recover from the tricaine sedation within less than 3 minutes when placed in fresh water. On the contrary, all individual gavaved with $20 \mu \mathrm{g} \cdot \mathrm{g}^{-1}( \pm$ )-anatoxin-a rapidly present (in the first 5 minutes) obvious signs of neurotoxic effects, comprising a complete stop or a rapid diminution of opercular 
movement, abnormal swimming with hemi- or complete paresis of the fins, accompanied with a global musculature rigidity. After $10 \mathrm{~min}$, only one individual even presents a few sporadic breathing activities, that completely stop after $15 \mathrm{~min}$, when all other organisms already present complete paresis and ventilation cease. After $30 \mathrm{~min}$, these individuals, presenting no sign of recovery, were considered as dying, if not dead, and euthanized, then were considered for further toxicological dose calculation. When $\mathrm{LD}_{100}$ and the NOAEL were observed at $20 \mu \mathrm{g} \cdot \mathrm{g}^{-}$ ${ }^{1}$ and $6.67 \mu \mathrm{g} \cdot \mathrm{g}^{-1}( \pm)$-anatoxin-a, respectively, the LD 50 was calculated as $11.5 \mu \mathrm{g} . \mathrm{g}^{-1}$ of $( \pm)$ anatoxin-a (Fig. 2A; table 3).

\section{Anatoxin-a toxico-kinetics}

Following gavage experiment of adult female medaka fish to NOAEL, we have quantified $( \pm)$-anatoxin-a in the guts, the livers and the muscles after $1 \mathrm{~h}, 3 \mathrm{~h}, 6 \mathrm{~h}, 12 \mathrm{~h}, 24 \mathrm{~h}, 3 \mathrm{~d}, 6 \mathrm{~d}$ and $10 \mathrm{~d}$, to monitor the dynamic of the anatoxin-a assimilation/depuration efficiency in these various compartments (Fig. 1B-D). The highest ( \pm )-anatoxin-a amount was observed just $1 \mathrm{~h}$ after the exposure, representing up to $15,789 \mu \mathrm{g} \cdot \mathrm{g}^{-1}$ in some individual livers, representing more than 100 times more anatoxin-a than in the livers of other organisms similarly gavaged, illustrating the relative individual variability of the anatoxin-a uptake and assimilation/elimination during our experimentation. Although fish tissues present a global individual variability, the larger amount of anatoxin-a was observed in livers, the guts, and in a lesser amount in the muscles after $1 \mathrm{~h}$, then the tissues present a rapid decrease of anatoxin-a contents. Almost no more anatoxin-a was detectable after $24 \mathrm{~h}$ in all tissues. The depuration rate was calculated for the 12 first hours of depuration as being of 57, 100 and 90\%, in guts, livers and muscles, respectively, leading to rapid elimination of the anatoxin-a that does no seems to bio-accumulate in any of the investigated fish tissues.

\section{Anatoxin-a effects on the liver metabolome}

To investigate the molecular effects induced by $( \pm)$-anatoxin-a NOAEL exposure, the liver metabolite composition was compared between ungavaged fish (control) and fish collected $1 \mathrm{~h}$, $3 \mathrm{~h}, 6 \mathrm{~h}, 12 \mathrm{~h}$ or $24 \mathrm{~h}$ after gavage. The same livers extracts than those extracted with $75 \%$ methanol and analysed for anatoxin-a quantification were investigated by LC-MS/MS for untargeted metabolomics. The spectral data of a total of 591 different analytes were then extracted by the optimized pipeline, and their respective quantification (determined from the area-under-the-peak signal) compared between the different time-course groups using multivariate statistical methods, including unsupervised principal component analysis (PCA) and supervised partial least-squares discriminate analysis (PLS-DA), together with univariate groups variance analyses (ANOVA). These analyses allow to to discriminate among the experimental groups according to the time-course of anatoxin-a exposure and elimination.

Although the analysed fish livers present a global metabolome variability (Fig. 3A), the ( \pm )anatoxin-a gavage seems to rapidly modify the specific amount of various metabolites which progressively retrieved their initial state, as observed on components 1-3 projection of the PCA (Fig. 3B). The 29 analytes that present significant variation between the different groups according to ANOVA $(\mathrm{P}<0.05)$ indicate a clear difference between the groups, as observed on heatmap with hierarchical clustering (Fig. 3D), with a rapid increase or decrease of the metabolite quantity that diminishes after few hours and almost recovers control levels after $24 \mathrm{~h}$ 
post-gavage (Fig. 3E). The supervised multivariate analysis (PLS-DA) model shows consistent $\mathrm{R}^{2}$ cumulative, $\mathrm{Q}^{2}$ cumulative and permutation scores (Fig. $3 \mathrm{~F}$ ). The most discriminating $\mathrm{m} / \mathrm{z}$ features in the PLS-DA model (Figure 3C) were selected based on their respective VIP score, which resulted in 25 compounds with VIP value higher than 2 (Table 4), on component 1 and/or 2 (both contributing to the experimental group discrimination). The molecular formulas of each VIP were proposed based on accurate mass measurement, true isotopic pattern, and their putative identification was attempted with Metfrag and GNPS according to additional respective MS/MS fragmentation patterns. Interestingly, the tricaine (MW 165.0794 Da) belong to this VIP list and presents, as one could expect, a clear increase between the Control and $1 \mathrm{~h}$ post-gavage fish livers (in relation with pre-gavage anaesthesia procedure by balneation in $0.1 \%$ tricaine), then a complete disappearance between 1 and $3 \mathrm{~h}$.

The list of other putatively annotated compounds comprises then various phospholipids $(n=9)$ belonging to the glycerol-phosphocholine group, all presenting comparable variation patterns among the experimental groups, with an initial drop of these metabolite quantities between the control and the 1-h group, then a progressive re-increase until an almost complete recovery of the initial metabolite amount within less than $24 \mathrm{~h}$. Those metabolites are directly related to lipid metabolism process and their successive decrease and increase within the liver may denote important lipid consumption by the organism and progressive recovery of the liver to an unstressed condition. On the contrary, the sole VIPs which relative quantities present an initial increase were an undetermined analyte (MW $1064.600 \mathrm{Da}$ ) and the adenosine, both retrieving their initial levels within less than $24 \mathrm{~h}$. Such adenosine transient increase may indicate stress-inducing ATP/ADP/cAMP metabolic conversion and/or intensification of hepatic blood circulation, as it also presents a direct effect on vasodilation of liver arteria (Robson \& Schuppan 2010). Although our experimental design does allow to discriminate the specific effects of the anatoxin-a from those of the tricaine anaesthesia alone, it overall shows that the organisms present a complete recovery $24 \mathrm{~h}$ after being gavaged with anatoxin-a single NOAEL dose.

\section{Discussion}

In the present study, the neurotoxicological response of medaka fish subjected to anatoxina appears comparable to that found in carp (Osswald et al., 2007a) and zebrafish (Carneiro et al., 2015) supporting the evidence for the existence of a similar mechanism of action. Whereas no apparent precursor effect appears when fish are gavaged with sub-acute doses of anatoxina, the symptoms observed in the fish exposed to a higher dose denote an all-or-nothing effect, comprising rapid and intense neurotoxic signs, that are compatible with the mechanism of toxic action of anatoxin-a in the nervous system that has been described so far for other vertebrates (Fawell et al., 1999). These symptoms comprise different manifestations of muscular paralysis that are likely due to the primary, and nearly irreversible, binding of the anatoxin-a, being an acetylcholine agonist, to the acetylcholine receptors of the cholinergic synapses of the neuromuscular junctions, leading to a continuous muscular contraction. Previous works indicate that below a certain level the effects appear to be transient, the animals being able to make a complete and rapid recovery, although the data available in the literature remains limited (Dittman and Wiegand 2006). 
Our dose-response toxicological analysis indicates that (+)-anatoxin-a exhibits toxicological reference dose of 5.75 and $3.33 \mu \mathrm{g} . \mathrm{g}^{-1}$ of medaka bodyweight for LD50 and NOAEL (corresponding to 11.5 and $6.67 \mu \mathrm{g}\left( \pm\right.$ )-anatoxin-a. $\mathrm{g}^{-1}$ - table 3 ), respectively. Indeed, as the unnatural (-)-anatoxin-a isomer was shown to insignificantly contribute to the global toxicity to the 1/1 racemic mixture of ( \pm )-anatoxin-a used in this study (MacPhail et al., 2007). These results are in remarkable agreement with precedent data obtained on other organisms. Indeed, previous investigations of anatoxin-a toxicity determined on mice that, when administered by single-dose gavage, (+)-anatoxin-a exhibits a LD50 and a NOAEL of above 5 and $3 \mu \mathrm{g}^{-g^{-1}}$ of body weight, respectively (Fawell et al., 1999). In addition, Stevens and co-workers (1991) have initially shown that (+)-anatoxin-a presents LD50 value of 16.2 and $6.7 \mu \mathrm{g} . \mathrm{g}^{-1}$ of body weight, for pure (+)-anatoxin-a and complex extract containing anatoxin-a dispensed by single gavage to mice. Taken together, those results suggest that medaka fish and mouse present very similar toxicological dose-response to (+)-anatoxin-a. However, as the sex and the development stage of the organisms can influence the sensitivity to toxicant, one should also consider that the dose-responses observed in the present work on adult female medaka may be slightly different for male or juvenile fishes.

In the present work, we have also investigated at the metabolome scale the molecular variations induced by the anatoxin-a exposure on the fish liver. Indeed, although anatoxin-a is known to primarily induce neuromuscular effects, it might also have collateral consequences for the exposed organism that could imply remarkable response of the liver, as this tissue constitutes the main organ for both energetic metabolism and detoxification processes (Qiao et al., 2016). For this reasons, many (eco)toxicological investigations have focussed on the molecular response to various toxicants, presenting different mode-of-action, on the specific liver response. Therefore, the acute effect of a NOAEL dose of anantoxin-a seems to mostly induce a transient decrease of the liver lipid contents. It might denote an increase the lipid consumption related to energetic needs of the organism under this toxicological stress. Such metabolic effects seem to be rapidly compensated, as the liver lipid contents are progressively retrieving their initial levels. This suggests that those organisms are capable of a substantial recovery from this toxicological stress within less than $24 \mathrm{~h}$.

In our experiments, the promptitude of the neuromuscular effects of anatoxin-a when administered by gavage are in agreement with previous investigation performed on mice (Fawell et al., 1999), suggesting that anatoxin-a might be rapidly assimilated by the organisms by crossing the intestine barrier and being widespread to the whole musculature within less than 2 minutes. When anatoxin-a producing cyanobacterial biofilm are accidentally ingested by dogs, the animals present the first appearance of neurotoxic symptoms within less than 5 minutes (Wood et al., 2007), testifying for very rapid assimilation of a toxinogenous dose of anatoxin-a released from the cyanobacterial biomass within the stomach. To date, the genuine mechanism of the anatoxin-a transfer through the intestinal epithelia remains undetermined. However, the promptitude of the observed effects suggests that this small molecule (MW $=165$ Da) may remain neutral in order to be able to sharply cross the intestinal barrier, potentially through passive paracellular diffusion (Dahlgren and Lennernäs 2019).

Our toxico-kinetics investigation has shown that no detectable amount of anatoxin-a was 
still observed in guts $12 \mathrm{~h}$ after the fish having been gavaged to a single NOAEL dose. Then, the medaka fish presents also a rapid elimination of the anatoxin-a that transiently have been addressed to the liver, and in a lesser extent to the muscle, indicating that it may not be accumulating anatoxin-a under those conditions. Interestingly, Osswald and co-workers (2011) have shown no significant bioaccumulation of anatoxin-a in the trout tissues when administered by balneation up to $5 \mathrm{mg} . \mathrm{L}^{-1}$ of anatoxin-a. Previously, Osswald et al. (2008) have also similarly shown no bioaccumulation of anatoxin-a by the Mediterranean mussel M. galloprovincialis, that has been otherwise shown to present high accumulation capability for various contaminants, such as microcystins (Vasconcelos 1995). Although they observed some anatoxin-a uptake from the surrounding water filtered by the animals (observed maximum accumulation efficiency $=11 \%$ ), this seemed rapidly reduced rather by the depuration process of phase II detoxification enzymes or by passive elimination processes. These data show that, as anatoxin-a is capable to rapidly penetrate the whole organism's body, and induces obvious and acute neurotoxicological effects within a minute, it may also be rapidly eliminated by classical excretion or depuration mechanisms.

\section{Conclusion}

In our gavage experiment of medaka fish to a single NOAEL dose of anatoxin-a, the toxin appears to have been rapidly eliminated and the molecular effects were no more perceptible within the fish liver metabolome after $24 \mathrm{~h}$.

These observations suggest that when the dose remains below the acute toxicological limit producing neurotoxicosis that can lethal consequences, the organism can make a completely and rapidly recovery, that seems not to induce obvious effects even if the exposure is repeated several times (Fawell et al. 1999). However, one could still suspect that chronic anatoxin-a exposure may induce more insidious long-term pathologies on the central nervous system (Lombardo and Maskos 2015). But this hypothesis remains to be explored.

Moreover, the accurate investigations of the fish flesh contamination by anatoxin-a under highest toxinogenous cyanobacterial proliferations, especially when, in nature, certain fish are potentially actively feeding on those biofilms (Ledreux et al., 2014), remain to be performed to provide convincing data supporting the evaluation of the associated risks.

\section{The authors declare not conflict of interest}

Author statement

Simon Colas: Investigation, formal analysis, visualisation, writing - originnal draft Charlotte Duval: Resources

Benjamin Marie: Conceptualization, Methodology, Supervision, writing - review and editing, funding acquisition

\section{Acknowledgements}

This work was supported by grant CRD from ANSES attributed to the Cyanariv project, lead by Catherine Quiblier. We are grateful to Arul Marie for his advice and to the support provided 
by the mass spectrometry platform (PtSMB) and the medaka fish facility of the Muséum National d'Histoire Naturelle (Paris). 


\section{References}

Aboal, M., Puig, M. A., Mateo, P., \& Perona, E. (2002). Implications of cyanophyte toxicity on biological monitoring of calcareous streams in north-east Spain. Journal of Applied Phycology 14(1), 49-56.

Anderson, B., Voorhees, J., Phillips, B., Fadness, R., Stancheva, R., Nichols, J., ... \& Wood, S. A. (2018). Extracts from benthic anatoxin-producing Phormidium are toxic to 3 macroinvertebrate taxa at environmentally relevant concentrations. Environmental toxicology and chemistry 37(11), 2851-2859.

Aráoz, R., Molgó, J., \& De Marsac, N. T. (2010) Neurotoxic cyanobacterial toxins. Toxicon 56(5), 813-828.

Bogialli, S., Bruno, M., Curini, R., Di Corcia, A., \& Laganà, A. (2006). Simple and rapid determination of anatoxin-a in lake water and fish muscle tissue by liquid-chromatography-tandem mass spectrometry. Journal of Chromatography A 1122(1-2), 180-185.

Bouma-Gregson, K., Kudela, R. M., \& Power, M. E. (2018). Widespread anatoxin-a detection in benthic cyanobacterial mats throughout a river network. PloS One 13(5), e0197669.

Carmichael, W. W., Biggs, D. F., \& Gorham, P. R. (1975). Toxicology and pharmacological action of Anabaena flos-aquae toxin. Science 187(4176), 542-544.

Carmichael, W. W. (1994). The toxins of cyanobacteria. Scientific American 270(1), 78-86.

Carneiro, M., Gutierrez-Praena, D., Osorio, H., Vasconcelos, V., Carvalho, A. P., \& Campos, A. (2015). Proteomic analysis of anatoxin-a acute toxicity in zebrafish reveals gender specific responses and additional mechanisms of cell stress. Ecotoxicology and environmental safety 120, 93-101.

Chong, J., Wishart, D. S., \& Xia, J. (2019). Using metaboanalyst 4.0 for comprehensive and integrative metabolomics data analysis. Current protocols in bioinformatics 68(1).

Dahlgren, D., \& Lennernäs, H. (2019). Intestinal Permeability and Drug Absorption: Predictive Experimental, Computational and In Vivo Approaches. Pharmaceutics 11(8), 411.

Dittmann, E., \& Wiegand, C. (2006). Cyanobacterial toxins-occurrence, biosynthesis and impact on human affairs. Molecular nutrition \& food research 50(1), 7-17.

Fawell, J. K., Mitchell, R. E., Hill, R. E., \& Everett, D. J. (1999). The toxicity of cyanobacterial toxins in the mouse: II anatoxin-a. Human \& experimental toxicology 18(3), 168-173.

Gugger, M., Lenoir, S., Berger, C., Ledreux, A., Druart, J. C., Humbert, J. F., ... \& Bernard, C. (2005). First report in a river in France of the benthic cyanobacterium Phormidium favosum producing anatoxin-a associated with dog neurotoxicosis. Toxicon 45(7), 919-928.

Greer, B., Maul, R., Campbell, K., \& Elliott, C. T. (2017) Detection of freshwater cyanotoxins and measurement of masked microcystins in tilapia from Southeast Asian aquaculture farms. Analytical and Bioanalytical Chemistry 409(16), 4057-4069.

Haddad, S. P., Bobbitt, J. M., Taylor, R. B., et al., Brooks, B. W. (2019). Determination of microcystins, nodularin, anatoxin-a, cylindrospermopsin, and saxitoxin in water and fish tissue using isotope dilution liquid chromatography tandem mass spectrometry. Journal of chromatography. A 1599, 66.

Kim Tiam, S., Gugger, M., Demay, J., Le Manach, S., Duval, C., Bernard, C., \& Marie, B. (2019). Insights into the Diversity of Secondary Metabolites of Planktothrix Using a Biphasic Approach Combining Global Genomics and Metabolomics. Toxins 11(9), 498.

Ledreux, A., Brand, H., Chinain, M., Bottein, M. Y. D., \& Ramsdell, J. S. (2014). Dynamics of ciguatoxins from Gambierdiscus polynesiensis in the benthic herbivore Mugil cephalus: trophic transfer implications. Harmful Algae 39, 165-174.

Lombardo, S., \& Maskos, U. (2015). Role of the nicotinic acetylcholine receptor in Alzheimer's disease pathology and treatment. Neuropharmacology 96, 255-262.

MacPhail, R. C., Farmer, J. D., \& Jarema, K. A. (2007). Effects of acute and weekly episodic exposures to anatoxin-a on the motor activity of rats: comparison with nicotine. Toxicology 234(1-2), 83-89.

Oberemm, A., Becker, J., Codd, G. A., \& Steinberg, C. (1999). Effects of cyanobacterial toxins and aqueous crude extracts of cyanobacteria on the development of fish and amphibians. Environmental Toxicology: An International Journal 14(1), 77-88.

Osswald, J., Rellan, S., Gago, A., \& Vasconcelos, V. (2007a). Toxicology and detection methods of the alkaloid neurotoxin produced by cyanobacteria, anatoxin-a. Environment international 33(8), 1070-1089. 
Osswald, J., Rellán, S., Carvalho, A. P., Gago, A., \& Vasconcelos, V. (2007b). Acute effects of an anatoxin-a producing cyanobacterium on juvenile fish-Cyprinus carpio L. Toxicon 49(5), 693-698.

Osswald, J., Rellán, S., Gago, A., \& Vasconcelos, V. (2008). Uptake and depuration of anatoxin-a by the mussel Mytilus galloprovincialis (Lamarck, 1819) under laboratory conditions. Chemosphere 72(9), 1235-1241.

Osswald, J., Azevedo, J., Vasconcelos, V., \& Guilhermino, L. (2011). Experimental determination of the bioconcentration factors for anatoxin-a in juvenile rainbow trout (Oncorhynchus mykiss). Proceedings of the International Academy of Ecology and Environmental Sciences 1(2), 77.

Puschner, B., Pratt, C., \& Tor, E. R. (2010). Treatment and diagnosis of a dog with fulminant neurological deterioration due to anatoxin-a intoxication. Journal of veterinary emergency and critical care 20(5), 518-522.

Qiao, Q., Le Manach, S., Sotton, B., Huet, H., Duvernois-Berthet, E., Paris, A., ... \& Marie, B. (2016). Deep sexual dimorphism in adult medaka fish liver highlighted by multi-omic approach. Scientific reports, 6, 32459.

Quiblier, C., Wood, S. A., Echenique-Subiabre, I., Heath, M., Villeneuve, A., \& Humbert, J. F. (2013). A review of current knowledge on toxic benthic freshwater cyanobacteria-ecology, toxin production and risk management. Water Research 47(15), 5464-5479.

Rellán, S., Osswald, J., Vasconcelos, V., \& Gago-Martinez, A. (2007). Analysis of anatoxin-a in biological samples using liquid chromatography with fluorescence detection after solid phase extraction and solid phase microextraction. Journal of Chromatography A 1156(1-2), 134-140.

Robson, S. C., \& Schuppan, D. (2010). Adenosine: tipping the balance towards hepatic steatosis and fibrosis. Journal of hepatology 52(6), 941-943.

Sivonen, K., Jones, G. (1999) Cyanobacterial toxins. In: Chorus, I., Bartram, J. (Eds.), Toxic Cyanobacteria in Water: a Guide to Their Public Health Consequences, Monitoring and Management. E \&FN Spon, London, pp. 41-111.

Stevens, D. K., \& Krieger, R. I. (1991). Stability studies on the cyanobacterial nicotinic alkaloid snatoxin-A. Toxicon 29(2), 167-179.

Triantis, T. M., Kaloudis, T., \& Hiskia, A. (2016). Determination of Anatoxin-a in Filtered and Drinking Water by LC-MS/MS. Handbook of Cyanobacterial Monitoring and Cyanotoxin Analysis, 408-412.

Vasconcelos, V. M. (1995). Uptake and depuration of the heptapeptide toxin microcystin-LR in Mytilus galloprovincialis. Aquatic Toxicology 32(2-3), 227-237.

Wonnacott, S., \& Gallagher, T. (2006). The chemistry and pharmacology of anatoxin-a and related homotropanes with respect to nicotinic acetylcholine receptors. Marine Drugs 4(3), 228-254.

Wood, S. A., Selwood, A. I., Rueckert, A., Holland, P. T.,... \& Cary, C. S. (2007). First report of homoanatoxin-a and associated dog neurotoxicosis in New Zealand. Toxicon 50(2), 292-301. 
Figure 1.

A

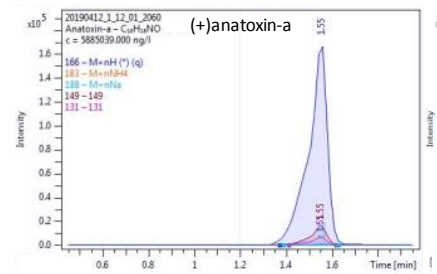

C

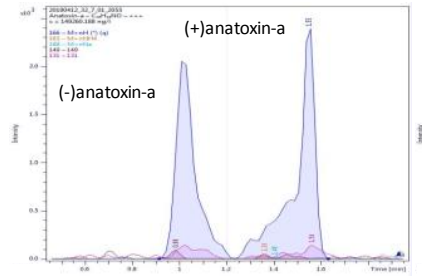

B

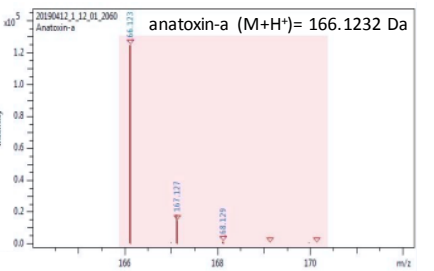

D

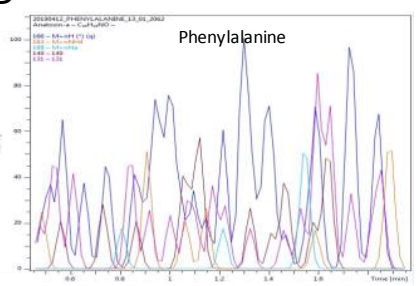

$E$

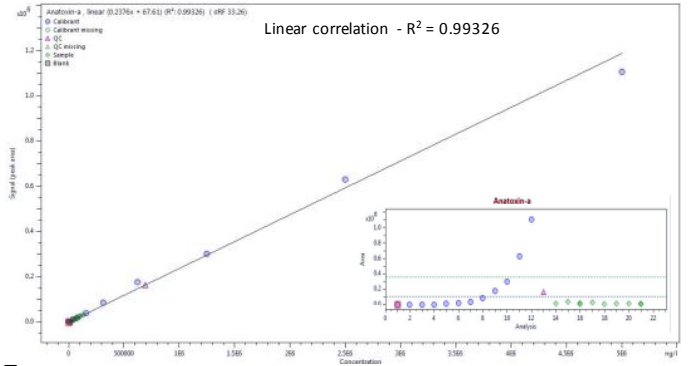

$\mathrm{F}$

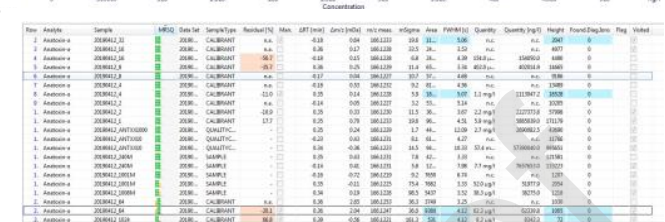

Figure 1. Anatoxin-a detection and quantification on HR qTOF mass spectrometer coupled to an UHPLC. The screening of (+)-anatoxin-a was performed according to the specific detection of analytes presenting accurate mass of the parent ion $\left(\mathrm{M}+\mathrm{H}^{+}=166.1232 \pm 0.001 \mathrm{Da}\right)$, accurate retention time $(1.55 \pm 0.2 \mathrm{~min}$, accurate isotopic pattern $(\mathrm{mSigma}<50)$ and co-detection of characteristic fragment ions $(149.096 \pm 0.001$ and $131.086 \pm 0.001 \mathrm{Da})(\mathrm{A}-\mathrm{B})$. The similar analyses of the ( \pm )-anatoxin-a can discriminate the (-) and the (+)-anatoxin-a that exhibits distinct retention times (1.1 and $1.6 \mathrm{~min}$, respectively) (C). No signal was detected with phenylalanine (D). Calibration curve performed with 12 serial dilutions of a certified standard of (+)-anatoxin-a (NRC, Canada) presenting applicable correlation factor (E). Example of a screening diagnostic table provided by TASQ ${ }^{\circledR}$ software for (+)-anatoxin-a quantification summarizing all qualitative and quantitative parameters for each sample $(\mathrm{F})$. 
Figure 2.

A

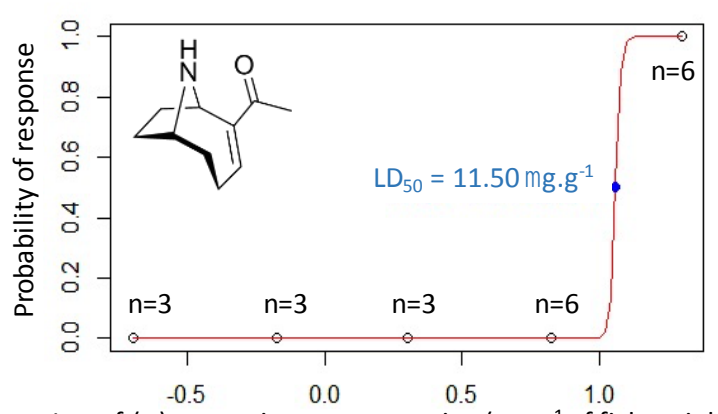

C

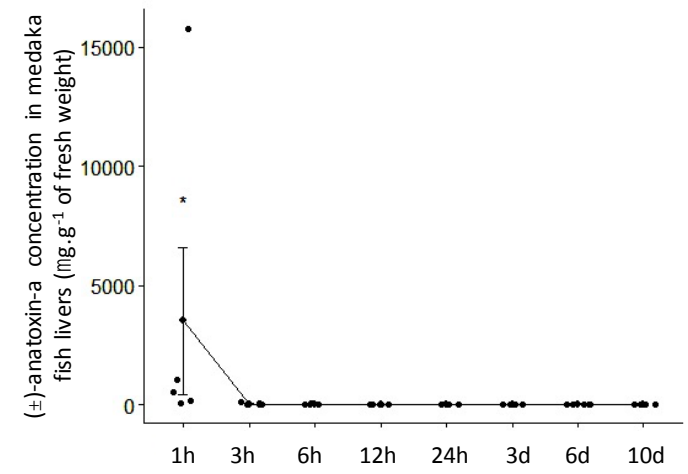

B

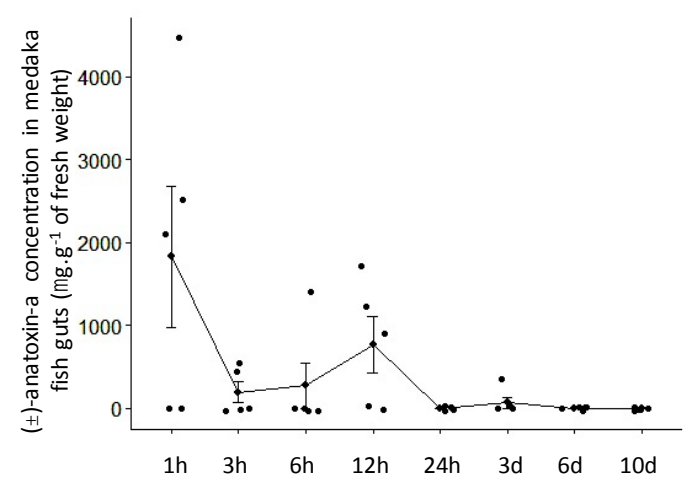

D

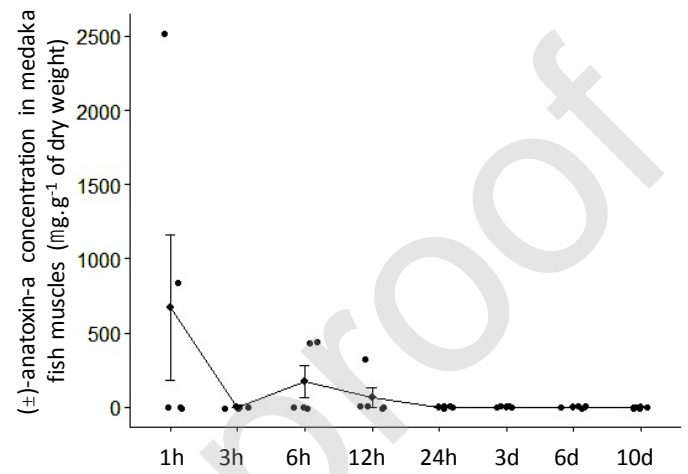

Figure 2. Anatoxin-a toxicity and toxico-kinetics on adult female medaka fish when administrated by singledose gavage. Estimation of the $\mathrm{LD}_{50}$ of $( \pm$ )-anatoxin-a by linear regression after log transformation ( $\mu \mathrm{g}$ of $\left( \pm\right.$ )-anatoxin-a.g ${ }^{-1}$ of fish mass) (A). Toxico-kinetics of ( \pm )-anatoxin-a administrated in a single NOAEL dose (6.67 $\mu \mathrm{g} . \mathrm{g}^{-1}$ fish weight) in the gut (B), the liver (C) and the muscle (D) after $1 \mathrm{~h}, 3 \mathrm{~h}, 6 \mathrm{~h}, 12 \mathrm{~h}, 24 \mathrm{~h}, 3 \mathrm{~d}, 6$ $\mathrm{d}$ or $10 \mathrm{~d}$ of depuration (n-5). On the 30 investigated individuals, only 6 of them does not present detectable amount of anatoxin-a, overall testifying for the global efficiency of the gavage experiments. 
Figure 3.
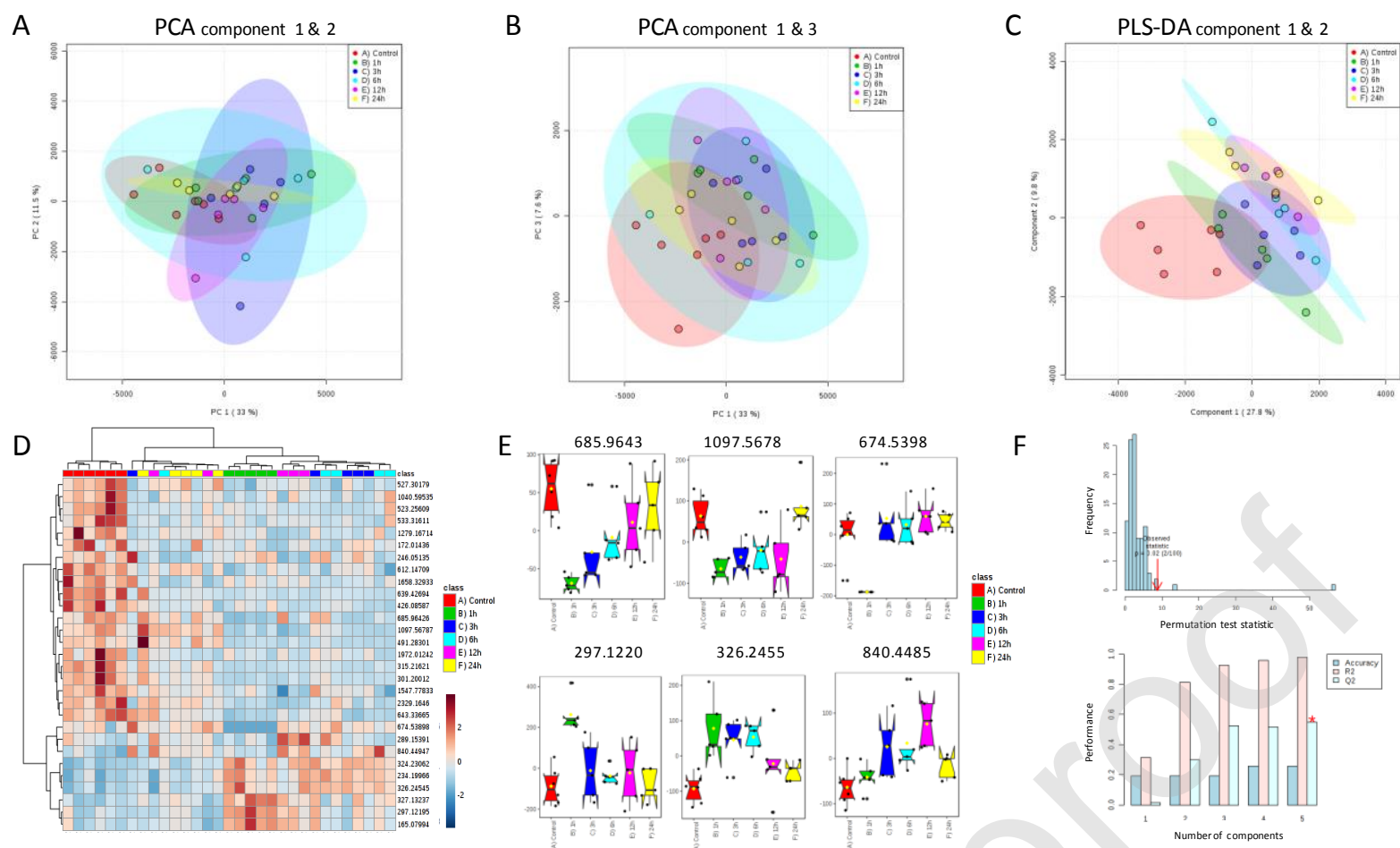

Figure 3. Metabolomics investigation of the liver metabolite variations after the administrated of a single NOAEL dose of $( \pm)$-anatoxin-a $\left(6.67 \mu \mathrm{g} \cdot \mathrm{g}^{-1}\right.$ fish weight) by gavage of adult female medaka fish in the liver after $1 \mathrm{~h}, 3 \mathrm{~h}, 6 \mathrm{~h}, 12 \mathrm{~h}$ and $24 \mathrm{~h}$. Individual score plots generated from a principal component analysis performed with the intensity count of 591 variables according to components 1-2 (A) and 1-3 (B). Heatmap representation with hierarchical classification (Ward clustering according to Euclidian distances) performed from relative intensities of the 29 significantly dysregulated analytes ( $P<0.05$ ANOVA) (D) and 6 examples of representative box-plots (E). Individual score plot generated from PLS-DA analysis performed with 591 extracted variables according to components 1-2 (C), and quality descriptors of the statistical significance and predictive ability of the discriminant model according to corresponding permutation and cross-validation tests $(\mathrm{F})$, respectively. 


\section{Tables}

\begin{tabular}{|cccc|}
\hline Phormidium strain & Acetone & Extraction solvant & \\
& Water & Methanol \\
PMC 1001.17 & $6436 \pm 139^{\mathrm{a}}$ & $5864 \pm 85^{\mathrm{b}}$ & $6689 \pm 158^{\mathrm{a}}$ \\
PMC 1007.17 & $2949 \pm 148^{\mathrm{b}}$ & $1467 \pm 88^{\mathrm{c}}$ & $3655 \pm 147^{\mathrm{a}}$ \\
PMC 1008.17 & $1773 \pm 95$ & $1420 \pm 103$ & $1913 \pm 192$ \\
\hline
\end{tabular}

Table 1. The efficiency of different protocols for anatoxin-a extraction from different cyanobacterial strains.

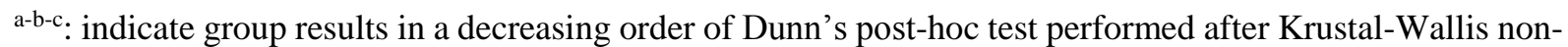
parametric tests.

\begin{tabular}{|c|c|c|c|c|c|c|}
\hline \multirow[t]{2}{*}{ Organ } & \multicolumn{2}{|c|}{ Recovery rate } & \multicolumn{2}{|c|}{$\begin{array}{l}\text { Limit of detection } \\
\text { (LOD) }\end{array}$} & \multicolumn{2}{|c|}{$\begin{array}{l}\text { Limit of quantification } \\
\text { (LOQ) }\end{array}$} \\
\hline & Method A & Method B & $\mu \mathrm{g} . \mathrm{L}^{-1}$ & $\mu g \cdot g^{-1}$ & $\mu \mathrm{g} . \mathrm{L}^{-1}$ & $\mu \mathrm{g} \cdot \mathrm{g}^{-1}$ \\
\hline $\mathrm{Gut}^{\mathrm{a}}$ & $78 \pm 13 \%$ & $126 \pm 22 \%$ & 0.412 & 20.6 & 1.25 & 62.5 \\
\hline Liver $^{\mathrm{a}}$ & $65 \pm 7 \%$ & $86 \pm 15 \%$ & 0.506 & 2.53 & 1.25 & 62.5 \\
\hline Muscle $^{\text {b }}$ & $25 \pm 4 \%$ & $51 \pm 3 \%$ & 0.546 & 14.52 & 1.25 & 285 \\
\hline
\end{tabular}

Table 2. The recovery rate, the limit of detection (LOD), and the limit of quantification (LOQ) of the two tested extraction procedure (A and $\mathrm{B}$, corresponding to pre-extraction or pre-analysis doping, respectively) measured on gut, liver and muscle of the medaka fish. ${ }^{\text {a }}$ determined on fresh weight; ${ }^{\text {b}}$ : determined on the dry weight.

\begin{tabular}{|c|c|c|c|c|}
\hline $\begin{array}{c}\text { Model } \\
\text { organism }\end{array}$ & $\begin{array}{c}\text { Toxicological } \\
\text { parameter }\end{array}$ & $\begin{array}{c}\text { Toxicological } \\
\text { values }\left(\mu \mathrm{g} \cdot \mathrm{g}^{-1}\right)\end{array}$ & $\begin{array}{c}\text { Formulation of the } \\
\text { toxicant }\end{array}$ & Reference \\
\hline Medaka fish & $\mathrm{LD}_{50}$ by gavage & 11.5 & $( \pm)$-anatoxin-a & This study \\
\hline Medaka fish & $\mathrm{LD}_{50}$ by gavage & $5.75^{*}$ & $(+)$-anatoxin-a & This study \\
\hline Medaka fish & $\mathrm{LD}_{100}$ by gavage & 20 & $( \pm)$-anatoxin-a & This study \\
\hline Medaka fish & $\mathrm{LD}_{100}$ by gavage & $10 *$ & $(+)$-anatoxin-a & This study \\
\hline Medaka fish & NOAEL by gavage & 6.67 & $( \pm)$-anatoxin-a & This study \\
\hline Medaka fish & NOAEL by gavage & $3.33^{*}$ & $(+)$-anatoxin-a & This study \\
\hline Zebrafish & $\mathrm{LD}_{100}$ by i.p. & 0.8 & $( \pm)$-anatoxin-a & Carneiro et al., 2015 \\
\hline Mouse & $\mathrm{LD}_{50}$ by i.v. & 0.1 & $(+)$-anatoxin-a & Fawell et al., 1999 \\
\hline Mouse & $\mathrm{LD}_{50}$ by gavage & {$[1-10]$} & $(+)$-anatoxin-a & Fawell et al., 1999 \\
\hline Mouse & NOAEL by gavage & 3 & $(+)$-anatoxin-a & Fawell et al., 1999 \\
\hline Mouse & $\mathrm{LD}_{50}$ by gavage & 6.7 & A. flos aquae NRC 44-1 & Stevens et al., 1991 \\
\hline Mouse & $\mathrm{LD}_{50}$ by gavage & 16.2 & $(+)$-anatoxin-a & Stevens et al., 1991 \\
\hline
\end{tabular}

* determined according to the theoretical 1/1 ( \pm )-racemic ratio, experimentally confirmed by LC-MS, considering as negligible the toxicity of (-)-anatoxin-a comparing to the 150-times higher toxicity of (+)anatoxin-a (Osswald et al., 2007).

Table 3. Summary of lethal concentration estimators determined for anatoxin-a by different administration pathways on different vertebrate models. 


\begin{tabular}{|c|c|c|c|c|c|c|c|}
\hline MW(Da) & RT (min) & $m / z$ & Annotation & Formula (neutral) & VIP Com. 1 & VIP Com. 2 & $\begin{array}{c}\text { Pattern } \\
\text { (C-1-3-6-12-24h) }\end{array}$ \\
\hline 541.3166 & 11.8 & 542.3224 & 1-icosapentaenoyl-sn-glycero-3-phosphocholine & $\mathrm{C}_{28} \mathrm{H}_{48} \mathrm{NO}_{7} \mathrm{P}$ & 8.40 & 6.37 & $|--|$ \\
\hline 569.3474 & 12.8 & 570.3537 & lysophosphatidylcholine $22: 5$ & $\mathrm{C}_{30} \mathrm{H}_{52} \mathrm{NO}_{7} \mathrm{P}$ & 7.14 & 5.92 & $|--|$ \\
\hline 525.2854 & 12.2 & 526.2908 & lysophosphatidylethanolamine 22:6 & $\mathrm{C}_{27} \mathrm{H}_{44} \mathrm{NO}_{7} \mathrm{P}$ & 6.62 & 7.32 & $|--|$ \\
\hline 499.2704 & 12.7 & 500.3048 & tauroursodeoxycholic acid & $\mathrm{C}_{26} \mathrm{H}_{45} \mathrm{NO}_{6} \mathrm{~S}$ & 4.52 & 3.88 & $\|--$ \\
\hline 519.3319 & 12.6 & 520.3384 & 1-linoleoyl-sn-glycero-3-phosphocholine & $\mathrm{C}_{26} \mathrm{H}_{50} \mathrm{NO}_{7} \mathrm{P}$ & 4.12 & 3.39 & 1--- \\
\hline 1248.619 & 5.5 & 625.3167 & . & $\mathrm{C}_{30} \mathrm{H}_{88} \mathrm{~N}_{24} \mathrm{O}_{29}$ & 3.20 & 2.32 & |---- \\
\hline 1134.671 & 12.4 & 1135.6760 & . & $\mathrm{C}_{58} \mathrm{H}_{90} \mathrm{~N}_{10} \mathrm{O}_{13}$ & 3.18 & 3.06 & |--- \\
\hline 1248.117 & 5.5 & 625.0657 & & $\mathrm{C}_{70} \mathrm{H}_{137} \mathrm{~N}_{17} \mathrm{O}_{2}$ & 2.85 & 2.03 & $\| 1-/ /$ \\
\hline 1082.640 & 11.8 & 1083.6469 & & $\mathrm{C}_{58} \mathrm{H}_{90} \mathrm{~N}_{4} \mathrm{O}_{15}$ & 2.80 & 2.03 & $|--|$ \\
\hline 267.0969 & 1.6 & 268.1040 & adenosine & $\mathrm{C}_{10} \mathrm{H}_{13} \mathrm{~N}_{5} \mathrm{O}_{4}$ & 2.74 & 1.89 & $|/-\||$ \\
\hline 131.0939 & 1.6 & 132.1010 & leucine & $\mathrm{C}_{6} \mathrm{H}_{13} \mathrm{NO}_{2}$ & 2.66 & 1.92 & |--- \\
\hline 612.1471 & 1.6 & 307.0808 & - & $\mathrm{C}_{24} \mathrm{H}_{37} \mathrm{O}_{12} \mathrm{PS}_{2}$ & 2.59 & 1.72 & $|--|$ \\
\hline 307.0837 & 1.3 & 308.0908 & glutathione & $\mathrm{C}_{10} \mathrm{H}_{17} \mathrm{~N}_{3} \mathrm{O}_{6} \mathrm{~S}$ & 2.51 & 2.13 & $|--| \mid$ \\
\hline 467.3016 & 12.0 & 468.3088 & 1-myristoyl-sn-glycero-3-phosphocholine & $\mathrm{C}_{22} \mathrm{H}_{46} \mathrm{NO}_{7} \mathrm{P}$ & 2.46 & 3.88 & |--/- \\
\hline 639.4269 & 4.6 & 320.7208 & - & $\mathrm{C}_{31} \mathrm{H}_{57} \mathrm{~N}_{7} \mathrm{O}_{7}$ & 2.45 & 1.61 & 1--- \\
\hline 523.2561 & 9.3 & 524.2634 & - & $\mathrm{C}_{23} \mathrm{H}_{42} \mathrm{NO}_{10} \mathrm{P}$ & 2.44 & 1.55 & ২--- \\
\hline 204.0911 & 3.5 & 205.0984 & tryptophan & $\mathrm{C}_{11} \mathrm{H}_{12} \mathrm{~N}_{2} \mathrm{O}_{2}$ & 2.41 & 1.68 & ২--- \\
\hline 165.0794 & 6.4 & 166.0868 & tricaine & $\mathrm{C}_{9} \mathrm{H}_{11} \mathrm{NO}_{2}$ & 2.40 & 3.56 & $\Lambda--$ \\
\hline 547.3283 & 13.6 & 548.3355 & - & $\mathrm{C}_{26} \mathrm{H}_{37} \mathrm{~N}_{13} \mathrm{O}$ & 2.16 & 1.45 & 1--- \\
\hline 1064.600 & 6.1 & 533.3073 & - & $\mathrm{C}_{30} \mathrm{H}_{84} \mathrm{~N}_{18} \mathrm{O}_{23}$ & 1.99 & 2.15 & $|/-\lambda|$ \\
\hline 543.3335 & 12.7 & 544.3400 & 1-arachidonoyl-sn-glycero-3-phosphocholine & $\mathrm{C}_{28} \mathrm{H}_{50} \mathrm{NO}_{7} \mathrm{P}$ & 1.91 & 2.66 & $1-/-$ \\
\hline 1050.577 & 12.2 & 1051.5843 & - & $\mathrm{C}_{56} \mathrm{H}_{82} \mathrm{~N}_{4} \mathrm{O}_{15}$ & 1.88 & 2.00 & 1--- \\
\hline 515.3015 & 11.3 & 516.3085 & lysophosphatidylcholine 18:4 & $\mathrm{C}_{26} \mathrm{H}_{46} \mathrm{NO}_{7} \mathrm{P}$ & 1.87 & 3.46 & $|---|$ \\
\hline 521.3476 & 13.6 & 522.3531 & 1-elaidoyl-sn-glycero-3-phosphocholine & $\mathrm{C}_{26} \mathrm{H}_{52} \mathrm{NO}_{7} \mathrm{P}$ & 1.80 & 7.50 & $\| 1-/ /$ \\
\hline 517.3184 & 11.9 & 518.3246 & 1-alpha-linolenoyl-sn-glycero-3-phosphocholine & $\mathrm{C}_{26} \mathrm{H}_{48} \mathrm{NO}_{7} \mathrm{P}$ & 1.58 & 2.18 & $1-/-$ \\
\hline
\end{tabular}

Table 4. List of the 25 VIP analytes that present score > 2 on either component 1 or component 2 of the PLS-DA analysis performed with all treatment groups, and their putative annotation according to their respective high-resolution mass, isotopic and MS/MS fragmentation patterns, searched against ChEBI, PubChem, HMDB and GNPS databases. "”, "“” and “-“ indicate when the metabolites globally decrease, increase or maintain their relative quantities between the time series, respectively. 


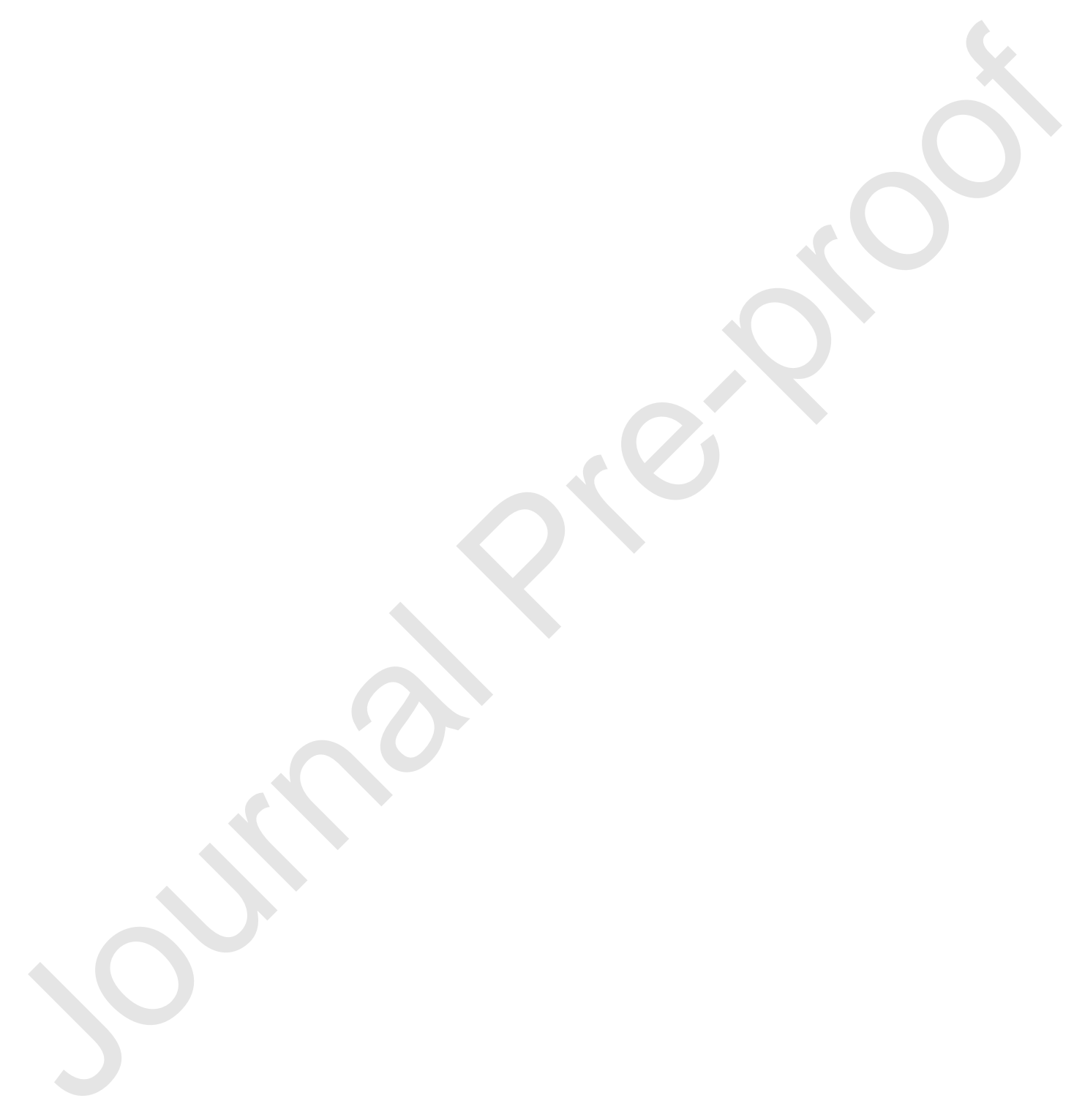

